\title{
Lipase-catalysed esters synthesis of cafestol and kahweol
}

\author{
Fábio Junior Moreira Novaes ${ }^{\mathrm{a}, \mathrm{b}}$, Ivaldo Itabaiana Junior ${ }^{\mathrm{c}}$, Felipe Korbus Sutili ${ }^{\mathrm{d}}$, \\ Philip John Marriott ${ }^{\mathrm{e}}$, Humberto Ribeiro Bizzo ${ }^{\mathrm{f}}$, Francisco Radler de Aquino Neto ${ }^{\mathrm{b}}$, \\ Rodrigo Octávio Mendonça Alves de Souza ${ }^{g}$, Claudia Moraes Rezende ${ }^{a, *}$
}

\footnotetext{
${ }^{a}$ Universidade Federal do Rio de Janeiro, Instituto de Química, Laboratório de Análise de Aromas, Avenida Athos da Silveira Ramos, 149, Bloco A, Sala 626, Rio de Janeiro, RJ 21941-895, Brazil

${ }^{\mathrm{b}}$ Universidade Federal do Rio de Janeiro, Instituto de Química, LADETEC, Avenida Horacio Macedo, 1281, Rio de Janeiro, RJ 21941-598, Brazil

${ }^{\mathrm{c}}$ Universidade Federal do Rio de Janeiro, Escola de Química, Departamento de Engenharia Bioquímica, Avenida Athos da Silveira Ramos, Bloco E, Sala E203, Rio de Janeiro, RJ 21941-909, Brazil

d Universidade Estadual Paulista - Campus Botucatu, Departamento de Engenharia de Bioprocessos e Biotecnologia, Rua José Barbosa de Barros, 1780, Lageado, SP 18610 307, Brazil

e Australian Centre for Research on Separation Science, School of Chemistry, Monash University, Wellington Road, Clayton, Victoria 3800, Australia

${ }^{\mathrm{f}}$ Embrapa Agroindústria de Alimentos, Avenida das Américas, 29501, Rio de Janeiro, RJ 23020-470, Brazil

${ }^{g}$ Universidade Federal do Rio de Janeiro, Instituto de Química, Laboratório de Biocatálise e Síntese Orgânica, Avenida Athos da Silveira Ramos, 149, Rio de Janeiro, RJ 21941-895, Brazil
}

\section{A R T I C L E I N F O}

\section{Keywords:}

Coffee diterpenes

Cafestol

Kahweol

Preparative scale isolation

Ester synthesis

Lipase catalyst

Cafestol ester

Kahweol ester

\begin{abstract}
A B S T R A C T
Cafestol and kahweol (C\&K), two coffee diterpene alcohols with structural similarity which exhibit anticarcinogenic effects, were isolated from green coffee Arabica beans, followed by their lipase-catalysed esterification and purification by preparative high-performance liquid chromatography (HPLC). The isolation and enzymatic synthesis parameters of C\&K esters were studied, with the latter optimised by a Central Composite Design; both procedures were monitored by gas chromatography. Scale up and improved isolation conditions resulted in $1.29 \mathrm{~g}$ of C\&K, with $98 \%$ purity from $300 \mathrm{~g}$ of green Arabica beans. The highest C\&K ester yields were observed using an alcohol:fatty acid molar ratio of $1: 5,73.3 \mathrm{mg} \mathrm{mL}^{-1}$ of CAL-B enzyme, $70^{\circ} \mathrm{C}$ and $240 \mathrm{rpm}$ for 3 days in toluene, leading to $85-88 \%$ conversion among a variety of tested $C \& K$ esters, including $n-C_{14: 0}-C_{20: 0}$, $\mathrm{C}_{18: 1}, \mathrm{C}_{18: 2}$ and $\mathrm{C}_{18: 3}$.
\end{abstract}

\section{Introduction}

Coffea arabica $\mathrm{L}$ is the richest coffee species in terms of its pleasant aroma and flavor. It also comprises a matrix with high content of cafestol and kahweol (C\&K), two ent-kaurane diterpene alcohols biogenetically modified by formation of a furan attached to the A ring at C3-C4 (Zhu, Luo \& Hong, 2014). C\&K are specific coffee components and correspond up to $2.5 \% \mathrm{w} / \mathrm{w}$ of bean composition, being the second most abundant class in coffee oil $(\leq 20 \%)$ after the triacylglycerides (75-85\%) (Speer \& Kölling-Speer, 2006). C\&K occur mainly in the esterified form (99.6\%) and are distributed as 24 different esters $\left(n-\mathrm{C}_{14: 0}\right.$, $\mathrm{C}_{16: 0}, \mathrm{C}_{16: 1}, \mathrm{C}_{17: 0}, \mathrm{C}_{18: 0}, \mathrm{C}_{18: 1}, \mathrm{C}_{18: 2}, \mathrm{C}_{18: 3}, \mathrm{C}_{20: 0}, \mathrm{C}_{20: 1}, \mathrm{C}_{22: 0}, \mathrm{C}_{24: 0}$, mainly palmitate and linoleate), with the corresponding diterpene alcohols as minor compounds (Kurzrock \& Speer, 2001). Among the esters, cafestol is the main diterpene present in the most important commercial species, C. arabica and C. robusta, and also in wild Coffea (Speer \& Kölling-Speer, 2006). As a biomarker of Arabica coffee, kahweol occurs in 1:2-2:1 ratio to cafestol, which may be absent in the Robusta coffee, or present in lower concentrations (Novaes, Oigman, Souza, Rezende \& Aquino Neto, 2015). Kahweol differs from cafestol by an unsaturation at carbons $\mathrm{C} 1-\mathrm{C} 2$ of the diterpene. In addition to these two diterpenes, Robusta coffee has also 16-O-methyl derivatives, considered to be biomarkers (Buchmann et al., 2010). By the presence and ratio of kahweol:16-O-methyl-cafestoI, it is possible to discriminate Arabica and Robusta coffees and predict their proportion in blendsblends (Buchmann et al., 2010).

The esterified diterpenes were first investigated by Kaufmann \& Hamsagar (1962). Decades later, Lam, Sparnins \& Wattenberg (1982) observed that C\&K palmitates were potent inducers of glutathione $S$ transferase activity against xenobiotic detoxification in intestinal and

\footnotetext{
* Corresponding author.

E-mail addresses: fabiojmnovaes@yahoo.com.br (F.J.M. Novaes), ivaldo@eq.ufrj.br (I. Itabaiana Junior), felipe.sutili@fca.unesp.br (F.K. Sutili), philip.marriott@monash.edu (P.J. Marriott), humberto.bizzo@embrapa.br (H.R. Bizzo), radler@iq.ufrj.br (F.R.d. Aquino Neto), rodrigosouza@iq.ufrj.br (R.O.M.A.d. Souza), crezende@iq.ufrj.br (C.M. Rezende).
} 
liver mucosa of mice. Then, it was found that the furan ring was vital for this activity, since the hydrogenated furan derivatives were inactive (Lam, Sparnins \& Wattenberg, 1987). In addition, C\&K palmitates proved to be carcinogenic inhibitors (McMahon et al., 2001; Huber et al., 2004; Majer et al., 2005; Higgins, Cavin, Itoh, Yamamoto \& Hayes, 2008; Moeenfard et al., 2016). In the free form, C\&K were shown to have anticarcinogenic, antioxidant, anti-inflammatory and hypercholesterolemic activities (Lee \& Jeong, 2007; Butt \& Sultan, 2011), suggesting their value as potential starting materials for new drugs.

The C\&K esters can be isolated from green coffee beans or produced by chemical synthesis from their free form, even though both procedures have low yields. Both degrade when exposed to a heated surface and in the presence of light or molecular oxygen, which is aggravated by long reaction times and by the use of acids or bases required for chemical esterification (Lam et al., 1982; Kurzrock \& Speer, 2001; Muhammad et al., 2008; Tsukui, Santos Júnior, Oigman, Souza, \& Rezende, 2014; Belandria et al., 2016).

Kaufmann \& Hamsagar (1962) were also the first to isolate the coffee diterpene esters. The authors identified six cafestol esters $\left(C_{16: 0}\right.$, $\mathrm{C}_{18: 0}, \mathrm{C}_{18: 1}, \mathrm{C}_{18: 2}, \mathrm{C}_{20: 0}, \mathrm{C}_{22: 0}$ ) isolated from a petroleum ether extract using TLC. Due to the difficulty of separation of kahweol esters from cafestol esters, kahweol esters were neither separately identified nor observed. In this same work, the authors were unable to isolate individual esters due to low product yield and so subsequently performed coffee oil saponification to obtain a C\&K mixture, followed by kahweol hydrogenation to increase the cafestol content. Then, it was subsequently submitted to chemical synthesis with several fatty acid chlorides $\left(\mathrm{C}_{14: 0}, \mathrm{C}_{16: 0}, \mathrm{C}_{18: 0}, \mathrm{C}_{18: 1}, \mathrm{C}_{18: 2}, \mathrm{C}_{20: 0}, \mathrm{C}_{20: 0}\right)$ in benzene/pyridine (3:1) to give the corresponding cafestol esters in $45-55 \%$ of yield. This method was reproduced by Kurzrock \& Speer (2001), Muhammad et al. (2008) and Finotello et al. (2017), where the latter two works employed 4-dimethylaminopyridine as catalyst but without improving on the yield $44-48 \%$ for cafestol palmitate (CP). When this system was tested for kahweol palmitate (KP), Muhammad et al. (2008) attained an 85\% yield, a somewhat surprising result since the two molecules are very similar and the reactive site being distant from the double bond that distinguishes them (Fig. 1).

Besides the difficulty to obtain better yields, isolation of the free diterpenes involves an exhaustive preparation step with extended lipid extraction time (generally Soxhlet apparatus, $\geq 5 \mathrm{~h}$ ), conventional saponification of coffee oil at prolonged reaction time under high temperature $\left(1-4 \mathrm{~h}, 70-90^{\circ} \mathrm{C}\right)$, laborious and consecutive fractionation by liquid-liquid extraction (LLE) and column, gel permeation or countercurrent chromatography (Lam et al., 1982; Kurzrock \& Speer, 2001; Muhammad et al., 2008; Chartier, Beaumesnil, Oliveira, Elfakir \& Bostyn, 2013). In addition, Dias, Faria, Mercadante, Bragagnolo, \& Benassi (2013) showed the poor efficacy of the coffee oil extraction to obtain free C\&K comparing four methods to extract the free coffee diterpenes from coffee beans: direct hot saponification (DHS), direct cold saponification (DCS), and Bligh and Dyer (BD) and Soxhlet (SO) extraction. The latter two were followed by saponification and LLE with $t$ butyl methyl ether (TBME). By use of high performance liquid chromatography (HPLC), they concluded that DHS was more efficient, presenting levels of C\&K 15\% higher than those obtained by DCS and $88 \%$ higher than those found by SO and BD.

Free and esterified C\&K are generally monitored by HPLC, but not simultaneously (Kurzrock \& Speer, 2001; Erny, Moeenfard, \& Alves, 2015). As the ester composition is complex and show coelutions, individual information on each compound is obtained only by separation using spectral deconvolution with different wavelengths, or selective ions monitoring using mass spectrometry detection (Kurzrock \& Speer, 2001; Chartier et al., 2013; Erny et al., 2015). Novaes et al. (2015) evaluated different means of sample injection methods for gas chromatography (GC) applied to monitor green coffee oil hydrolysis. The authors used a medium polarity column, capable of differentiating the structurally similar free C\&K and their respective esters. Although C\&K are somewhat thermolabile, and their esters are high-molecular mass compounds, the authors performed a non-derivatised GC analysis without evidence of degradation and negligible discrimination in the split/splitless injector when operated under pulsed split injection mode. This essentially reproduced the data obtained by using cold on-column

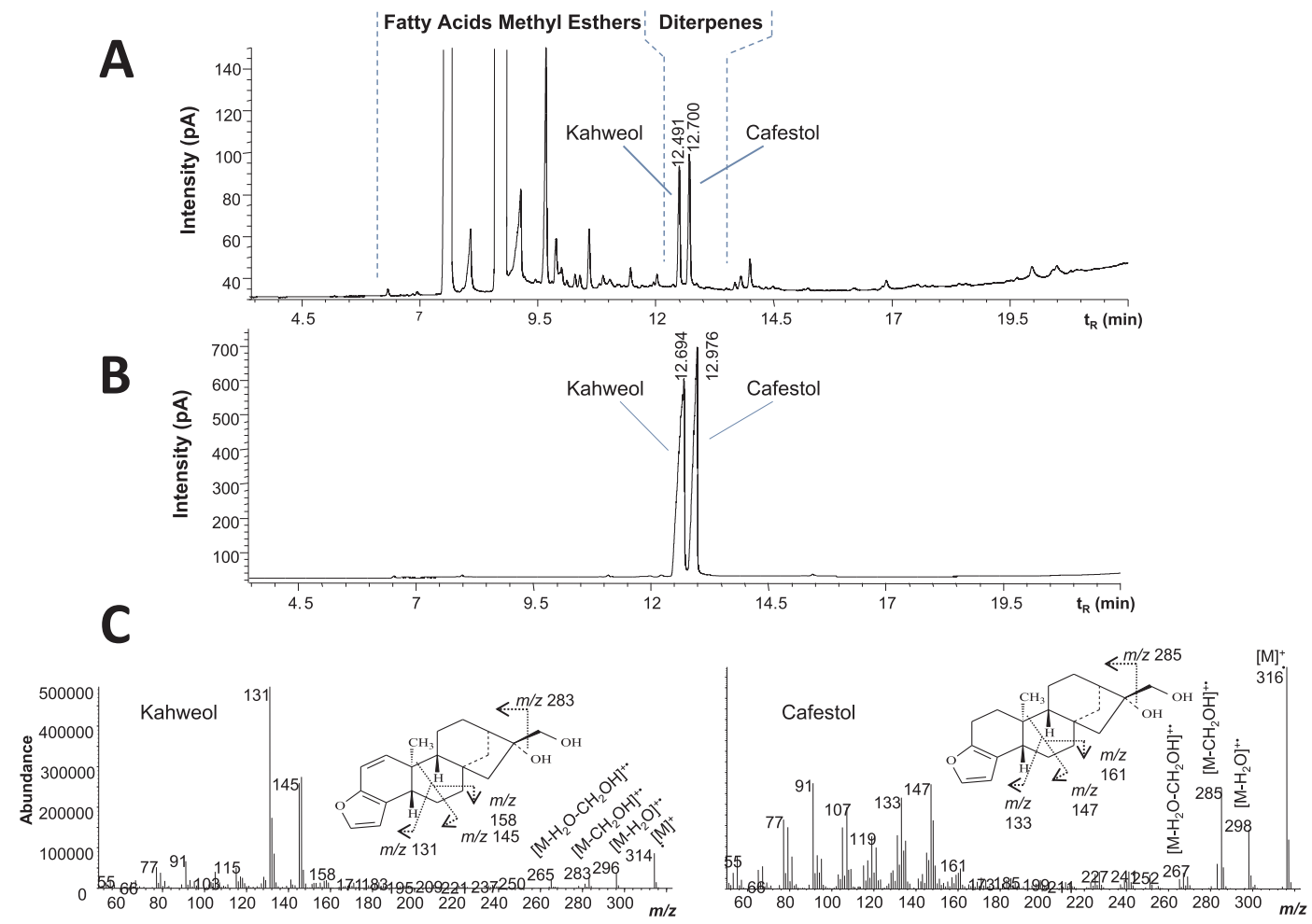

Fig. 1. GC-FID chromatograms of cafestol and kahweol A) TBME extract, B) after FCC purification and C) cafestol and kahweol mass spectra obtained by GC-MS. 
injection also evaluated in this work. Therefore, both GC inlet systems proved to be useful to monitor C\&K esterification, with pulsed split/ splitless mode easiest to operate.

An interesting synthetic approach to circumvent the low yield of chemical catalysed C\&K esterification reaction is to use biocatalysis, especially via lipase. Lipases (Enzyme Nomenclature EC 3.1.1.3) are a class of enzymes with physiologic application to hydrolysis reactions, however with a broad applicability to acidolysis, alcoholysis, amilasys, esterification and transesterification reactions in organic solvent with low-water content (Aguieiras, Cavalcanti-Oliveira, \& Freire, 2015). This route has been reported as a potential substitute to chemical processes; favourable features include milder reaction conditions, better reaction control, higher-quality products and low energy costs (Lee, Chaibakhsh, Rahman, Basri \& Tejoa, 2010). However, the yield, reaction time, enzyme stability and other parameters should be investigated for the target application (Su, Li, Fan, \& Yan, 2015). Following our efforts to develop new enzyme-mediated protocols, herein we report the optimisation of reaction parameters for the enzymatic esterification of C\&K isolated from coffee bean, mediated by Novozyme $435^{\circledR}$. In parallel, this work describes improvements in C\&K isolation from green Arabica coffee beans, and in GC analyses to monitor C\&K and their esterification products.

\section{Materials and methods}

\subsection{Enzymes and chemicals}

A C\&K mixture was isolated (see below) from Brazilian C. arabica L. green (unroasted) bean. Palmitic acid (>98\%) was obtained from Vetec Química Fina Ltda (Duque de Caxias, RJ, Brazil) and other fatty acids $\left(n\right.$ - $\left.\mathrm{C}_{14: 0}, \mathrm{C}_{18: 0}, \mathrm{C}_{18: 1}, \mathrm{C}_{18: 2}, \mathrm{C}_{18: 3}, \mathrm{C}_{20: 0} ; \geq 98 \%\right)$ from SigmaAldrich (St. Louis, MO). Novozyme $435^{\oplus}$ (CAL-B, Candida antarctica lipase $\mathrm{B}$ immobilised on a macroporous acrylic resin; specific activity: $10,000 \mathrm{U} . \mathrm{g}^{-1}$ ) was purchased from Novozymes (Shanghai, China). Molecular sieves ( $3 \AA$, 8.12 mesh) were purchased from Sigma-Aldrich. All solvents were of analytical or chromatographic grade (TEDIA Company, Fairfield, OH). A stock solution of both C\&K at a concentration of $25 \mathrm{mg} \mathrm{L}^{-1}$ in toluene was prepared, and was diluted with the same solvent to produce analytical calibration standards.

\subsection{Analytical method}

The GC method was adapted from Novaes et al. (2015), originally proposed for crude coffee oil analysis, but altered to use a shorter capillary column (from 10 to $5 \mathrm{~m}$ ) and a faster oven temperature program. This GC procedure maintains acceptable chromatographic resolution, results in a run time almost half of the original condition, while reducing the elution temperature of C\&K and their esters by about 6 and $24^{\circ} \mathrm{C}$, respectively, which is important for thermolabile compound analysis. For this purpose, a GC (Agilent 6890; Agilent Technologies, Palo Alto, CA) equipped with a HP 7673 auto sampler and coupled in parallel to a flame ionisation detector (FID) and an Agilent 5973N quadrupole mass spectrometer (qMS) was used to monitor the reactions. Helium (99.9992\%) carrier gas was at $2 \mathrm{~mL} \mathrm{~min}^{-1}$ in constant flow mode. Injection was made in a pulsed split mode at $330^{\circ} \mathrm{C}$ with a pressure pulse of $25 \mathrm{psi}$ during the initial $15 \mathrm{~s}$, thereafter maintaining a split ratio of 1:50; the injection volume was $1.0 \mu \mathrm{L}$. A DB-17HT capillary column ( $50 \%$ phenyl $50 \%$ methylsiloxane, $5 \mathrm{~m}, 0.25 \mathrm{~mm}$ i.d., film thickness $0.15 \mu \mathrm{m}$; J\&W Scientific/Agilent Technologies, Folsom, CA) was employed and the oven was programmed from $90{ }^{\circ} \mathrm{C}(0.25 \mathrm{~min})$ to $327^{\circ} \mathrm{C}$ at $12^{\circ} \mathrm{C} \mathrm{min}^{-1}$. The FID was set to $340^{\circ} \mathrm{C}$ and qMS transfer line at $340^{\circ} \mathrm{C}$. Mass spectra (MS) were obtained in scan mode (50-800 Da),

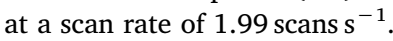

Analytical curves for C\&K in toluene over a calibration range of $0.1-25.0 \mathrm{mg} \mathrm{L}^{-1}$ were obtained by external standardisation and performed in triplicate. Response linearity of C\&K was determined by the least squares method and expressed by the correlation coefficient $\left(\mathrm{r}^{2}\right)$. Finally, the conversion of C\&K esters was calculated from the percentage of molar concentration of the diterpene alcohols C\&K consumed, as follows:

Conversion rate $(\%)=100-(C \mathrm{t} / C$ ix 100$)$

where $C i$ is the initial concentration of cafestol or kahweol at the beginning of the reaction, obtained by the analytical curve, and $\mathrm{Ct}$ is the concentration at a given reaction time.

\subsection{Isolation of $C \& K$}

Unroasted coffee beans $(300 \mathrm{~g}$ ) were saponified with $800 \mathrm{~mL}$ of $2.5 \mathrm{M} \mathrm{KOH}$ (Vetec Química Fina) in methanol. The flat-bottomed flask (3 $\mathrm{L}$ ) was stirred for $1 \mathrm{~h}$ at room temperature and $800 \mathrm{rpm}$ using an overhead stirrer (IKA Eurostar 60 digital package, Staufen, Germany). Then, $800 \mathrm{~mL}$ of water was added to terminate the reaction and the C\& $\mathrm{K}$ mixture was extracted using $800 \mathrm{~mL}$ of TBME. The extract was concentrated using a rotary evaporator, diluted further with $300 \mathrm{~mL}$ of heptane, and then extracted with $300 \mathrm{~mL}$ of $10 \%$ aqueous methanol. The methanol extract was evaporated, resulting in around $20 \mathrm{~g}$ of an amber oil. It was diluted in a minimal amount of hexane/ethyl acetate $(1: 1, v / v)$, and directly transferred using a Pasteur pipette to the head of a flash chromatography column (FCC), followed by a small plug of glass wool on the top of the column phase.

Purification by FCC used a $40 \mathrm{~cm}, 3 \mathrm{~cm}$ i.d. column packed with $30 \mathrm{~g}$ of flash silicagel (Vetec Química Fina), using hexane/ethyl acetate (1:1, $v / v)$ as mobile phase $\left(v=2.5 \mathrm{~cm} \mathrm{~min}^{-1}\right)$. Fractions were collected into $10 \mathrm{~mL}$ vials; fractions $14-23$ contained the $\mathrm{C} \& \mathrm{~K}$ mixture, and were characterised by reference to standards by GC-FID and GC-qMS (Section 2.2). Solvent was removed by vacuum to constant mass.

\subsection{Hansen solubility parameters (HSP)}

Hansen solubility parameters in practice (HSPiP) software (Version 4.0, Hansen-Solubility, Horsholm, Denmark) was used to calculate the three HSP components (hydrogen bonds, dispersion and intermolecular forces) for C\&K, such as for initial screening of solvents for C\&K lipasecatalysed esterification.

\subsection{Lipase-catalysed reaction: Preparation of C\&K esters using central composite rotational design (CCRD)}

One milliliter from the stock solution of both C\&K $\left(25 \mathrm{mg} \mathrm{mL}^{-1}\right)$ was used for each reaction performed in this study. Similarly, solutions of fatty acid of known concentrations $\left(205 \mathrm{mg} \mathrm{mL}^{-1}\right.$ or 2 equivalent mass) were prepared and $0.5 \mathrm{~mL}$ was used in order to have a molar ratio between the diterpene alcohol and fatty acid of 1:5. One hundred and ten milligrams of the immobilised enzyme were individually weighed in $2 \mathrm{~mL}$ vials, which received the C\&K and fatty acid substrates and then were sealed with an airtight screw cap. The esterification reactions were incubated in a shaker over 3 days at $240 \mathrm{rpm}$ and $70^{\circ} \mathrm{C}$, and the conversions were measured by GC-FID, with the products identified by GC-qMS (Section 2.2).

\subsection{Isolation of C\&K ester by preparative liquid chromatography (Prep-LC)}

The reaction mixture was transferred to a $0.50 \mathrm{~mL}$ LC syringe and separated in a Shimadzu LC (Kyoto, Japan) equipped with two LC-6AD high pressure pumps, DGU-20A degasser and model SPD-20AV UV-vis detector to obtain separate C\&K palmitate peaks. A Luna $5 \mu \mathrm{m}$ phenylhexyl preparative column $(250 \times 21.2 \mathrm{~mm}$, Phenomenex, Aschaffenburg, Germany) was kept at $25^{\circ} \mathrm{C}$ during the analysis. The mobile phase consisted of $100 \%$ methanol at a flow rate of $10 \mathrm{~mL} \mathrm{~min}^{-1}$. Detection was carried out at $220 \mathrm{~nm}$ based on UV absorption spectra of C\&K. This procedure allowed baseline separation for 
C\&K esters; KP eluted between 15.1 and 15.9 min, while CP eluted from 16.3 to $17.2 \mathrm{~min}$. These were collected separately in $25 \mathrm{~mL}$ bottles, and the solvent removed by vacuum to constant mass.

\section{Results and discussion}

\subsection{Isolation of free $C \& K$}

In order to obtain free C\&K for subsequent esterification studies, an adaption of DHS procedure from Dias et al. (2013) was performed. Therefore, a preparative scale C\&K isolation using an increased mass of ground coffee beans was employed according to the volume of alkaline solution used. Dias et al. (2013) applied $0.2 \mathrm{~g}$ of sample to $2 \mathrm{~mL} 2.5 \mathrm{M}$ $\mathrm{KOH}$ (a ratio $\left(\mathrm{g} \mathrm{mL}^{-1}\right)$ of 1:10), while the proportion employed here was of 1:2.7 ( $300 \mathrm{~g}$ of unroasted coffee beans and $800 \mathrm{~mL}$ of $2.5 \mathrm{M}$ $\mathrm{KOH})$. While the scaled-up approach was not as efficient as that of the Dias method, the lower ratio of 1:2.7 reduced the amount of reagent required, and recovered substantial $\mathrm{C} \& \mathrm{~K}$ product. After that, $\mathrm{C} \& \mathrm{~K}$ were extracted with TBME from the reaction mixture; a purification step was required in order to eliminate co-extracted fatty acids (Fig. 1A). For this reason, Tsukui et al. (2014) developed a FCC method with ethyl acetate and hexane (3:7) as mobile phase, for C\&K purification. For FCC purification, an adequate time difference between elution of impurities and the diterpenes allowed an increase in solvent strength of ethyl acetate: hexane from 30 to $50 \% v / v$ to accelerate elution of diterpenes and reduce excess solvent. The TBME extract was chromatographed by FCC and eluates were collected every $10 \mathrm{~mL}$ for GC analysis. These were grouped, concentrated and weighed, followed by GC-FID and GC-qMS, which confirmed the presence of C\&K, their ratio, and purity (Fig. 1B and C). The FCC extract provided a white solid of mass $1.29 \mathrm{~g}$, with purity of $98 \%$ of the C\&K diterpene mixture (47:53) (Fig. 1B), equivalent to $0.43 \% w / w$ of the composition of the green Arabica coffee bean. This adapted method was performed in a single batch of $8 \mathrm{~h}$ and the final result was consistent with the range $0.2-1.9 \% w / w$ of C\&K, as indicated by Kurzrock \& Speer (2001).

\subsection{Lipase-catalysed C\&K esterification}

In order to evaluate the efficiency of the lipase-catalysed esterification of C\&K with palmitic acid, Novozyme $435^{\circledR}$ lipase was chosen, as it was already known to have good esterification activity for a large number of substrates including other kaurane alcohol diterpenes (Monsalve, Rosselli, Bruno \& Baldessari, 2005) and related compounds with vicinal hydroxyl groups like sucrose, arabitol, and $\beta$-sitosterol (Franssen, Steunenberg, Scott, Zuilhof \& Sanders, 2013).

An important parameter for enzymatic reactions is the correct choice of solvent, which should drive the reaction in the desired direction (Duan, Wei \& Liu, 2010). Solvent choice is based on the solubility of substrates and products, as well as on stability and catalytic activity of the enzyme (He et al., 2010). In general, lipase catalysed esterification reactions are performed in aliphatic hydrocarbon solvents. However, C\&K are insoluble in such solvents. Thus, the use of more polar solvents was required, and Hansen Solubility Parameters (HSP) were used for selection (Hansen, 2007). HSP predicts the miscibility of two or more substances and it is based on the product of three co-ordinated forces (hydrogen bonds, dispersion and intermolecular forces) calculated for each compound. Relative energy differences between the substances informs about their solubility. Thus, HSP was calculated for palmitic acid and C\&K, and compared with several solvents (Table S1). Four solvents (acetone, TBME, toluene and acetonitrile) with relative energy difference $\Delta \delta_{\text {Total }} \leq 10$, were considered as good solvents, and chosen to screen the performance of Novozyme $435^{\circledR}$ to convert C\&K into their respective fatty esters (Table 1). These solvents were evaluated on lipase catalysed reactions using suitable conditions for esterification reactions, such as: $1.5 \mathrm{~mL}$ of solvent, C\&K $(0.08 \mathrm{M})$, palmitic acid (2 equivalents mass) as acyl donor and
Novozyme $435^{\circledR}$ as catalyst $(60 \mathrm{mg})$, at $50^{\circ} \mathrm{C}$ and $140 \mathrm{rpm}$. Reactions were successfully monitored over five days by GC-FID and the products identified by GC-qMS (Fig. 2; see Figs. S1-S4 in Supporting Information for further details).

From the first day, all solvents tested resulted in the formation of the two desired esters, KP and $\mathrm{CP}$, both monoesterified at the primary hydroxyl (-OH) group at C17 (Fig. 2A, D and E). Although there is a tertiary $-\mathrm{OH}$ available at $\mathrm{C} 16$ in the $\mathrm{C} \& \mathrm{~K}$ structure, the steric hindrance effect does not allow fatty acid incorporation. This was also observed for the biocatalyst-esterification of other related alcohols with tertiary -OH groups, confirming the CAL-B region selectivity towards the more available acidic hydrogens (Franssen et al., 2013).

Different MS profiles can be observed between C\&K palmitates (Fig. 2D and E), despite the structural similarity between the compounds, distinguished by an unsaturation at $\mathrm{C}_{1}-\mathrm{C}_{2}$. Characteristic ions are the molecular ion $[\mathrm{M}]^{+}$. at $m / z 552$ for $\mathrm{KP}$ and $m / z 554$ for CP; water loss at $m / z 534$ and $m / z 536\left[\mathrm{M}-\mathrm{H}_{2} \mathrm{O}\right]^{+}$. via tertiary hydroxyl elimination, followed by fatty acid loss to produce $m / z 278$ and $m / z$ $280\left[\mathrm{M}-\mathrm{H}_{2} \mathrm{O}-\mathrm{RCO}_{2} \mathrm{H}\right]^{+}$. and the ion derived from palmitic acid at $\mathrm{m} / \mathrm{z}$ $239 \mathrm{RCO}^{+}$are features of the MS. Other ions of the diterpene moiety are $m / z 131 / 145 / 158$ and $m / z 133 / 147 / 161$ (Figs. 1 and 2). The results obtained by GC-qMS analyses were consistent with those reported by Lam et al. (1982) and our previous study (Novaes et al., 2015).

Among the solvents evaluated, toluene showed the best conversion after 3 days with a slight increase in conversion after the third day of reaction, reaching $47 \%$ after five days using the initial conditions studied. This can be related to the higher hydrophobicity of toluene (log $P=2.5$ ), as solvents with $\log P>2$ are proposed to maintain a constant degree of enzyme hydration during esterification, as proposed by Laane, Boeren, Vos \& Veeger (2009). These authors stated that solvents with higher $\log P$ are more effective in esterification rather than those that better solubilise the substrates. However, an opposite correlation between $\log P$ value and reaction rate was observed for acetonitrile (log $P=-0.33)$, acetone $(\log P=-0.23)$, and TBME $(\log P=1.4)$ (Fig. 2B). Liu, Zhang, Tan, Yan \& Hammed (2010) suggested that the lipase activity is also dependent on the functional group of the organic solvent due to the absorption of water in the catalytic cavity of the enzyme, and so changes in its secondary structure and dynamic properties occur. The authors also verified, using acetone and acetonitrile, an increase of 1.5-2.5-fold in the initial esterification activity $\left(\mathrm{U} \mathrm{mg}^{-1} \mathrm{~g}^{-1}\right)$ in three immobilised lipases, including Novozyme $435^{\circledR}$. By FT-IR analysis, Yang et al. (2012) observed an increase of $\alpha$-helix form (\%) and a decrease in random coil (\%) for acetone and acetonitrile, more pronounced for the latter solvent, which can explain the higher conversion to $\mathrm{C} \& \mathrm{~K}$ palmitates in acetonitrile than in acetone and TBME (Fig. 2B and C).

Acetone showed the same behaviour as toluene on lipase esterification, but with lower conversion. With acetonitrile and TBME, the enzyme was not active after the first day, as no improvement in conversion was observed. However, after the first day, lipase esterification with acetonitrile was shown to be better than acetone even after 5 days (Figs. 2B and S5). Adachi, Nagae \& Matsuno (1999) verified that the water content is important to maintain the activity of CAL-B enzyme in reactions using acetonitrile, reaching a maximum of activity with $1 \%$ of water, after which the yield tends to fall until enzyme deactivation. The water produced in the esterification reaction can induce a conformational change at the active site of the enzyme and decrease substrate accessibility (Castro \& Anderson, 1995), or it may shift the equilibrium towards the direction of the reactants, causing hydrolysis. In order to analyse the influence of water released during the esterification reaction in toluene, the reaction profile was repeated using $3 \AA$ molecular sieves (Table S2 in Supplementary Information). However, no significant improvement in product yield was observed with the adsorption of the generated water.

Unwanted by-products such as the dehydro-diterpenes (Fig. 2C) were observed in the more favoured conditions, i.e. in the presence of 
Table 1

Partition coefficients and Hansen Solubility Parameters for lipase-catalysed esterification of coffee diterpenes.

\begin{tabular}{|c|c|c|c|c|c|c|c|c|}
\hline Substance & $\log P^{1}$ & $\delta \mathrm{D}^{2}$ & $\delta \mathrm{P}^{3}$ & $\delta \mathrm{H}^{4}$ & $\delta_{\text {Total }}^{5}$ & & $\Delta \delta_{\text {Total }}^{6}$ & \\
\hline Cafestol & - & 18.6 & 3.4 & 7.8 & 20.4 & Cafestol-solvent & Kahweol-solvent & Palmitic acid-solvent \\
\hline Kahweol & - & 18.6 & 4.1 & 8.1 & 20.7 & & & \\
\hline Palmitic acid & - & 16.3 & 3.4 & 6.0 & 17.6 & & & \\
\hline Acetonitrile & -0.33 & 18.0 & 6.1 & 15.3 & 24.4 & 4.0 & 3.7 & 6.8 \\
\hline Acetone & -0.23 & 10.4 & 7.0 & 15.5 & 19.9 & 0.5 & 0.8 & 2.3 \\
\hline TBME & 1.43 & 14.8 & 4.3 & 5.0 & 16.2 & 4.2 & 4.5 & 1.4 \\
\hline Toluene & 2.50 & 1.4 & 2.0 & 18.0 & 18.2 & 2.2 & 2.5 & 0.6 \\
\hline
\end{tabular}

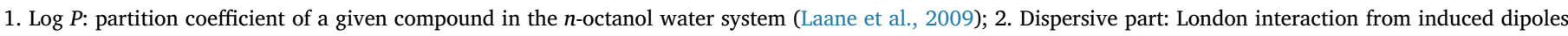

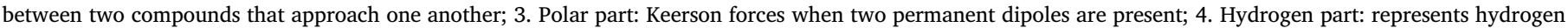

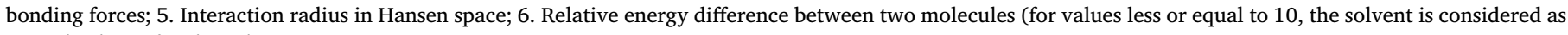
a good solvent for the solute).
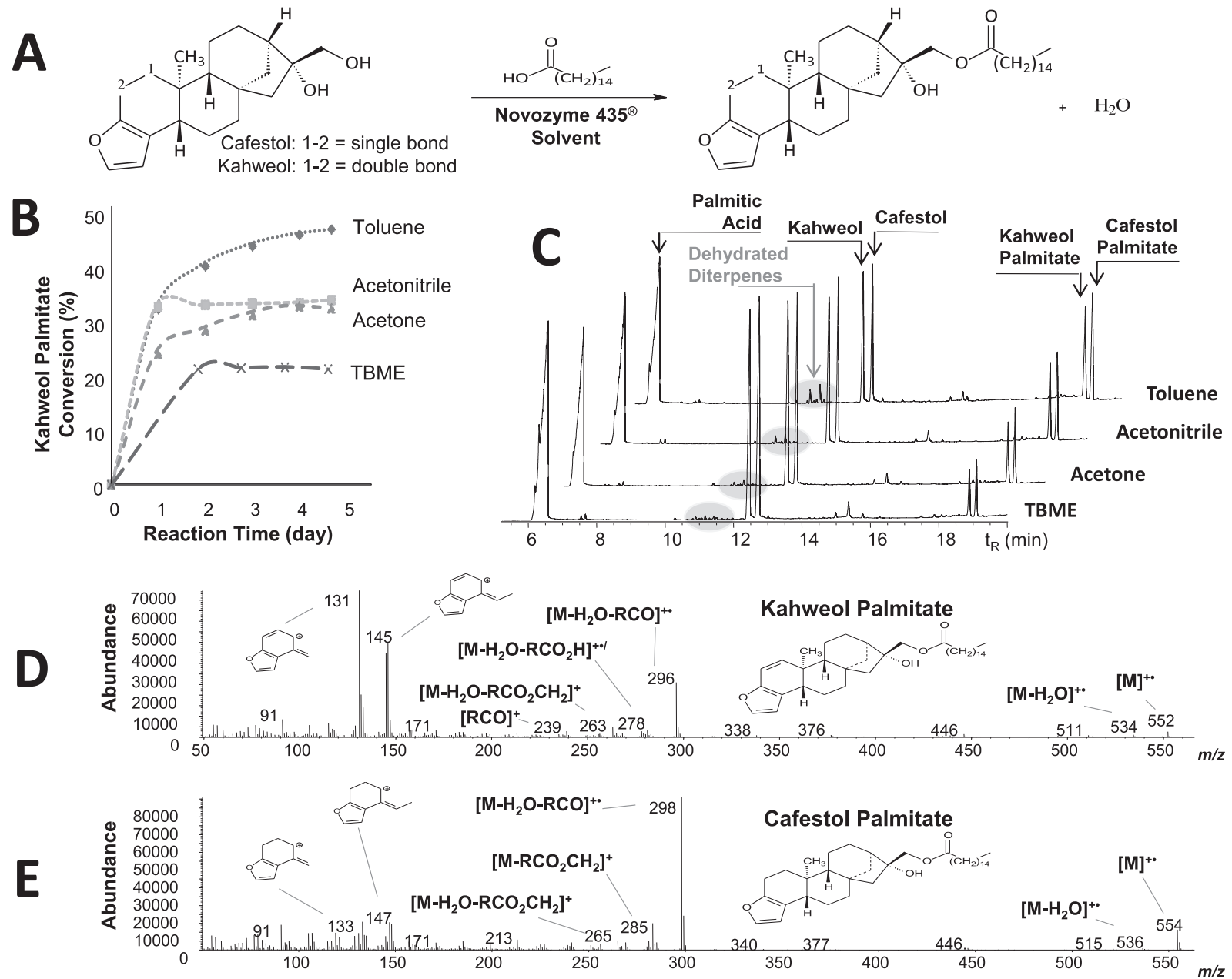

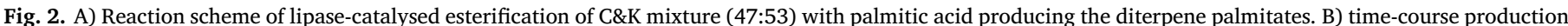

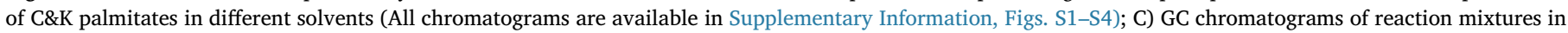

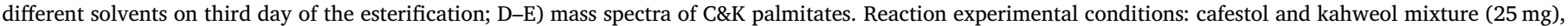
palmitic acid (2 equiv., $40.5 \mathrm{mg}$ ) as acyl donor, and $60 \mathrm{mg}$ of Novozyme $435^{\circledR}$ in solvent $(1.5 \mathrm{~mL})$ at $50{ }^{\circ} \mathrm{C}$ and $140 \mathrm{rpm}$ monitored during 5 days.

toluene or acetonitrile (Fig. 2C). It is noteworthy that no product of esterification of the dehydro-diterpenes was observed and which, if formed, would elute at a region in the chromatogram after C\&K alcohols and before C\&K esters (see Figs. S1-S4, Supporting Information for further details). Control reactions of C\&K in the absence of lipase or fatty acids were also performed in toluene over three days, at the same conditions, and no by-product was observed (data not shown). These dehydro-diterpenes are also formed by long exposure of C\&K to heated surfaces, such as in the coffee roasting process, or in the presence of alkaline catalyst, two reaction conditions that promote this kind of side- reaction (Speer \& Kölling-Speer, 2006; Dias et al., 2013; Novaes et al., 2015).

\subsection{Increase of $C \& K$ ester conversion using central composite rotational design (CCRD)}

In order to increase conversion of C\&K to esterification products, the variables that influence the reaction were investigated in a Central Composite Rotational Design (CCRD; also called Central Composite Circumscribed design, or CCC) $2^{4}$ model with five replicates at the 
Table 2

Experimental design and results of CCRD for the enzyme catalysed esterification of $\mathrm{C} \& \mathrm{~K}$.

\begin{tabular}{|c|c|c|c|c|c|c|}
\hline \multirow[t]{2}{*}{ Entry } & \multicolumn{4}{|c|}{ Variable levels" } & \multicolumn{2}{|c|}{ Conversion (\%) } \\
\hline & $\begin{array}{c}\mathrm{T} \\
\left({ }^{\circ} \mathrm{C}\right)\end{array}$ & $\begin{array}{c}\mathrm{E} \\
(\mathrm{mg})\end{array}$ & $\begin{array}{c}\text { SMR } \\
\text { (Ac/Al) }\end{array}$ & $\begin{array}{c}\text { St } \\
(\mathrm{rpm})\end{array}$ & $\begin{array}{c}\text { Kahweol } \\
\text { Palm. }\end{array}$ & $\begin{array}{c}\text { Cafestol } \\
\text { Palm. }\end{array}$ \\
\hline 1 & $-1(40)$ & $-1(35)$ & $-1(2)$ & $-1(90)$ & 12.3 & 12.4 \\
\hline 2 & $-1(40)$ & $-1(35)$ & $-1(2)$ & $+1(190)$ & 25.8 & 21.0 \\
\hline 3 & $-1(40)$ & $-1(35)$ & $+1(4)$ & $-1(90)$ & 21.8 & 21.5 \\
\hline 4 & $-1(40)$ & $-1(35)$ & $+1(4)$ & $+1(190)$ & 28.8 & 24.2 \\
\hline 5 & $-1(40)$ & $+1(85)$ & $-1(2)$ & $-1(90)$ & 18.8 & 21.6 \\
\hline 6 & $-1(40)$ & + $1(85)$ & $-1(2)$ & $+1(190)$ & 31.0 & 30.5 \\
\hline 7 & $-1(40)$ & +1 (85) & $+1(4)$ & $-1(90)$ & 28.6 & 32.3 \\
\hline 8 & $-1(40)$ & $+1(85)$ & $+1(4)$ & $+1(190)$ & 40.4 & 41.2 \\
\hline 9 & $+1(60)$ & $-1(35)$ & $-1(2)$ & $-1(90)$ & 35.4 & 34.6 \\
\hline 10 & $+1(60)$ & $-1(35)$ & $-1(2)$ & $+1(190)$ & 49.5 & 50.1 \\
\hline 11 & $+1(60)$ & $-1(35)$ & $+1(4)$ & $-1(90)$ & 43.7 & 43.9 \\
\hline 12 & $+1(60)$ & $-1(35)$ & $+1(4)$ & $+1(190)$ & 64.2 & 64.0 \\
\hline 13 & $+1(60)$ & $+1(85)$ & $-1(2)$ & $-1(90)$ & 48.6 & 50.0 \\
\hline 14 & $+1(60)$ & $+1(85)$ & $-1(2)$ & $+1(190)$ & 60.8 & 59.7 \\
\hline 15 & $+1(60)$ & $+1(85)$ & $+1(4)$ & $-1(90)$ & 58.7 & 60.3 \\
\hline 16 & $+1(60)$ & $+1(85)$ & $+1(4)$ & $+1(190)$ & 71.3 & 69.4 \\
\hline 17 & $-2(30)$ & $0(60)$ & $0(3)$ & $0(140)$ & 17.8 & 15.6 \\
\hline 18 & $+2(70)$ & $0(60)$ & $0(3)$ & $0(140)$ & 68.2 & 64.9 \\
\hline 19 & $0(50)$ & $-2(10)$ & $0(3)$ & $0(140)$ & 21.3 & 21.8 \\
\hline 20 & $0(50)$ & $+2(110)$ & $0(3)$ & $0(140)$ & 53.3 & 54.6 \\
\hline 21 & $0(50)$ & $0(60)$ & $-2(1)$ & $0(140)$ & 29.6 & 25.7 \\
\hline 22 & $0(50)$ & $0(60)$ & $+2(5)$ & $0(140)$ & 54.1 & 55.5 \\
\hline 23 & $0(50)$ & $0(60)$ & $0(3)$ & $-2(40)$ & 58.6 & 57.2 \\
\hline 24 & $0(50)$ & $0(60)$ & $0(3)$ & $+2(240)$ & 47.8 & 46.8 \\
\hline $25(C)$ & $0(50)$ & $0(60)$ & $0(3)$ & $0(140)$ & 42.3 & 42.4 \\
\hline $26(\mathrm{C})$ & $0(50)$ & $0(60)$ & $0(3)$ & $0(140)$ & 42.8 & 42.2 \\
\hline $27(\mathrm{C})$ & $0(50)$ & $0(60)$ & $0(3)$ & $0(140)$ & 43.9 & 43.8 \\
\hline $28(C)$ & $0(50)$ & $0(60)$ & $0(3)$ & $0(140)$ & 43.6 & 43.7 \\
\hline $29(\mathrm{C})$ & $0(50)$ & $0(60)$ & $0(3)$ & $0(140)$ & 44.6 & 43.1 \\
\hline \multirow{3}{*}{\multicolumn{2}{|c|}{ Entry 25-29 }} & \multicolumn{3}{|c|}{ Average Value } & 43.4 & 43.0 \\
\hline & & \multicolumn{3}{|c|}{ Standard Deviation } & 0.91 & 0.73 \\
\hline & & \multicolumn{3}{|c|}{ Relative Standard Deviation (\%) } & 2.1 & 1.7 \\
\hline
\end{tabular}

* Temperature (T, $\left.{ }^{\circ} \mathrm{C}\right)$; Enzyme load (E, mg); Substrate molar ratio (SMR, Ac/ $\mathrm{Al}$ ); Stirring (St, rpm); Centre Point (C). All chromatograms are available in Supplementary Information (Fig. S6).

centre point. Temperature $\left(\mathrm{T},{ }^{\circ} \mathrm{C}\right)$, amount of lipase (E, mg), substrate molar ratio (SMR, acid/alcohol) and stirring (St, rpm) were chosen based on previous experience in this group (Itabaiana Junior et al., 2013) and detailed experimental description is presented in Supplementary Information. Reaction time was kept at 3 days based on the screening previously performed (Figs. $2 \mathrm{~B}$ and $\mathrm{S} 5$ ). The variables and their coded values from CCRD $2^{4}$ (actual settings of parameters are given in parentheses), are presented along with the respective results in Table 2. The experimental design and data analysis were performed using Statistic software version 6.0 (Statsoft, Inc., USA). All chromatograms are available in Supplementary Information (Fig. S5).

Both diterpenes were esterified at moderate conversions, with small variations between them, as shown for the centre point replicates in entries 25-29 (Table 2), which also demonstrates an excellent reproducibility for these experiments with relative standard deviation $<3 \%$ (Table 2). The highest conversion is shown in experiment 16 with $71.3 \%$ and $69.4 \%$ for kahweol and cafestol palmitates, respectively, which is ca. 30\% higher than Kaufmann \& Hamsagar (1962), Kurzrock \& Speer (2001) and Finotello et al. (2017) obtained by chemical catalysis, who reported between $45 \%$ and $55 \%$ of conversion. Muhammad et al. (2008) reported $44 \%$ and $85 \%$ for CP and KP, respectively.

The experimental data were adjusted to the proposed model by analysis of variance (ANOVA) (Table S3 in Supplementary Information). The model was validated by $F$-test, where $F_{\text {Calculated }}>F_{\text {Tabulated }}$, and it was also observed that both the linear and quadratic terms are statistically important, as well as all second-order interactions, except $E \times S M R, E \times S$ t and $S M R \times S t$ for $\mathrm{KP}$ and $T \times E$, $E \times S M R$ and $S M R \times S t$ for $C P$ which were considered insignificant $(P$ value $>0.05$ ) and were excluded, benefiting the model by reducing the number of coefficients. The correlation coefficients were 0.9086 for $\mathrm{KP}$ and 0.9279 for CP.

Temperature proved to have the most positive effect with the highest influence on conversion, followed by the amount of enzyme, acyl donor (SMR) and stirring (Table S3 in Supplementary Information). Higher temperatures lower the viscosity of the medium, improve solubility of substrates and enhance mass transfer, besides increasing the kinetic energy by accelerating collisions between enzyme and substrates, and improving initial velocity of the reaction (Li, Sun, Li, Liu \& Huang, 2014). Due to the high boiling point of toluene $\left(110.6^{\circ} \mathrm{C}\right)$ and the thermal stability of the enzyme, higher temperatures $\left(60-70^{\circ} \mathrm{C}\right)$ could be applied in the time interval considered, without enzyme deactivation due to denaturation. Larger amounts of enzyme provides a greater number of active sites for acyl-enzyme complex formation and further increases the probability of collisions is further increased, by increasing the amount of acyl donor, which even in excess did not inhibit the enzyme activity (Entry 22, Table 2) (Soo, Salleh, Basri, Rahman \& Kamaruddin, 2004). Stirring plays an important role in enhancing mass transfer. Mild speed may cause a slight increment to conversion or was not efficient, while excessive stirring force can damage the enzyme support (Li et al., 2014). According to our CCRD experimental model, an increase in stirring improves the mass transfer and reaction conversion (Fig. 3 and Supplementary Information Fig. S7), even though a small damage of enzyme support has been observed by the Scanning Electronic Microscopy of Novozyme $435^{\circledR}$ support before and after lipase-catalysed C\&K esterification (Fig. S8 in Supporting Information).

Fig. 3 shows the response surface graphs that illustrate the effect of each variable on the conversion to KP (Fig. S7 in Supporting Information for $\mathrm{CP}$ conversion). It suggests the use of upper axial points of each variable $(+2$ on Table 2$)$ to increase the reaction conversion (Fig. 3). These values - enzyme load of $110 \mathrm{mg}$ (7.3\% w/w), SMR of $5: 1,70{ }^{\circ} \mathrm{C}$ and $240 \mathrm{rpm}$ - were inserted in the mathematical model, which predicts a conversion of around $100 \%$ for KP and $97 \%$ for $\mathrm{CP}$, both with $95 \%$ confidence interval (Table S4 in Supporting Information). The experimental result, using the upper axial points, yielded a conversion of $86.6 \pm 0.2 \%$ for $\mathrm{KP}$ and $85.7 \pm 0.2 \%$ for $\mathrm{CP}$ (Table 3 and Fig. S9), proved to be more efficient than the best result of the CCRD (Entry 16, Table 2), and lower than predicted values. This difference between predicted and experimental values was expected due to the regression coefficients ( 0.9086 for KP and 0.9279 for $\mathrm{CP})$ and by the fact that the experimental results were obtained for extrapolated points related to the model. It is worth noticing that the use of upper axial points increased the conversions. These yields were confirmed later by gravimetry using preparative HPLC for isolation of C\&K palmitates from the reaction mixture (Fig. S10 in Supporting Information). Provided by the literature, an unusual HPLC condition with $100 \%$ methanol and a phenyl-hexyl preparative column allowed baseline separation for C\&K esters. To the best of our knowledge, it was the first description where this separation could be achieved by HPLC.

In order to evaluate the scope of the method developed so far we chose the optimised reaction conditions presented above for the synthesis of other diterpene esters $\left(n-\mathrm{C}_{14: 0}, \mathrm{C}_{18: 0}, \mathrm{C}_{18: 1}, \mathrm{C}_{18: 2}, \mathrm{C}_{18: 3}\right.$, $\mathrm{C}_{20: 0}$ ), as shown in Table 3. All chromatograms and mass spectra are available in Supplementary Information (Figs. S9-S16).

The reaction with other fatty acids also occurred with high yield, with a minimum of $84.7 \pm 0.3 \%$ for cafestol myristate and maximum of $88.2 \pm 0.8 \%$ for kahweol arachidate (Table 3). A small effect of carbon-chain-length was observed and was enough to increase the conversion around $1 \%$ for each additional $-\mathrm{CH}_{2}$ in the hydrocarbon chain, presumably resulting from the regio-specificity of the enzyme due to its lipophilic substrate preference (Soultani, Engasser \& Ghoul, 2001). On the other hand, higher unsaturation degree tended to the 

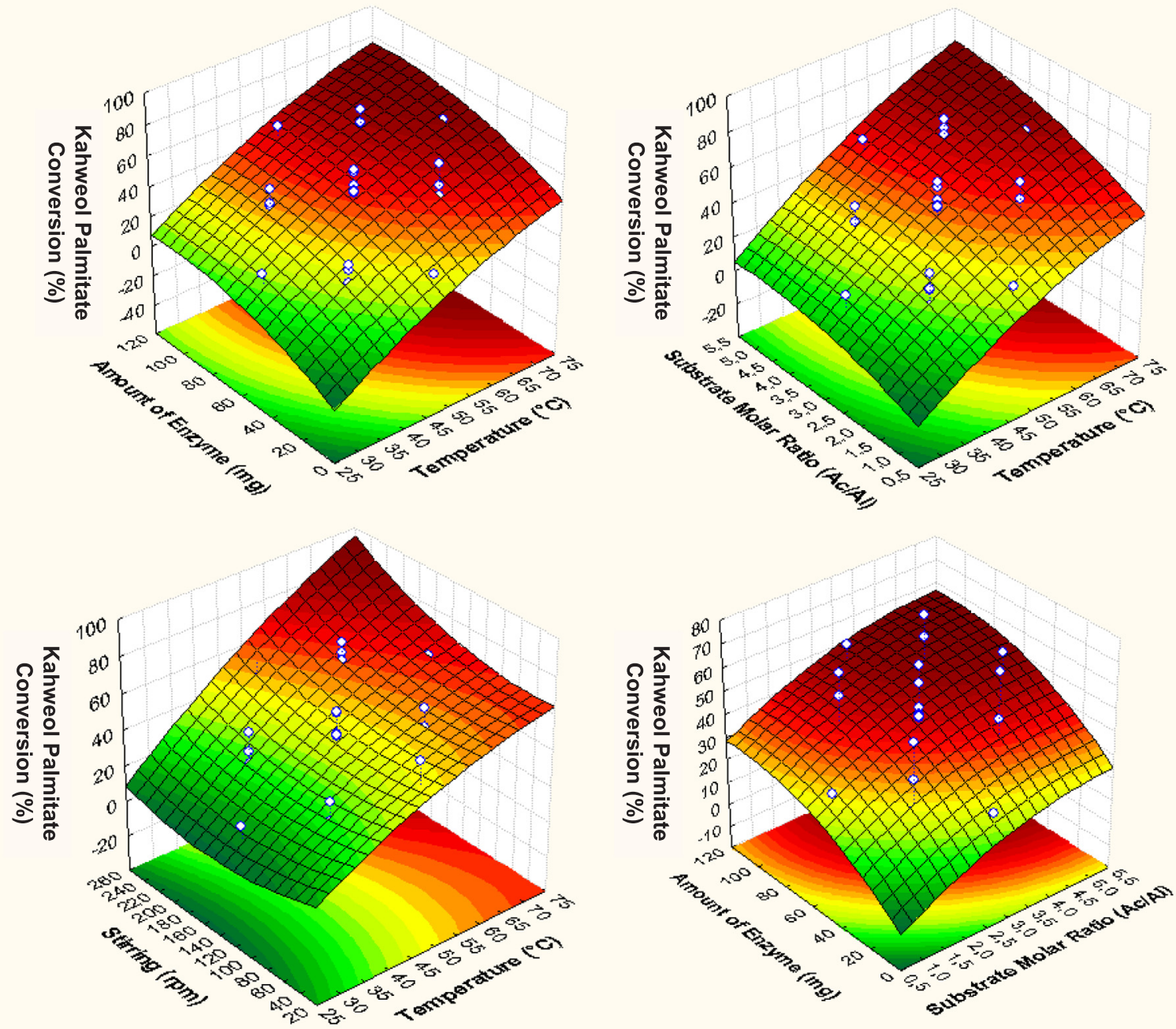

Fig. 3. Response surface for kahweol palmitate production by Novozyme $435^{\circledR}$ in toluene from the Central Composite Design (CCRD, $2^{4}$ ) model. Parameters levels $(-2,-1,0,+1$, and +2$)$ are described in Table 2 and symbolised here by the white solid spheres on the response surfaces: Temperature $\left(30,40,50,60\right.$ and $\left.70{ }^{\circ} \mathrm{C}\right)$, amount of enzyme $(10,35,60,85$, and $110 \mathrm{mg})$, substrate molar ratio $(1,2,3,4$, and 5) and stirring $(40,90,140,190$, and $240 \mathrm{rpm})$.

opposite. Reaction with stearic acid is slightly preferred as compared to the corresponding reactions with unsaturated long-chain fatty acids such as oleic, linoleic and linolenic acids, whose yields were reduced by increasing the degree of unsaturation (Table 3). The double bond provides a decrease in the flexibility of the acyl donor structure, hindering its access to the active site of the enzyme (Otto et al., 2000).

\section{Conclusion}

A process to isolate a C\&K mixture was performed and resulted in recovery of around $1.3 \mathrm{~g}$ of the coffee diterpenes from $300 \mathrm{~g}$ of green Arabica coffee beans in a single batch in $8 \mathrm{~h}$, with $>98 \%$ purity. The Hansen Solubility Parameter proved to be a simple tool for the choice of the reaction solvent for C\&K biocatalysed esterification, avoiding unnecessary waste of reagents and time for solubility testing; toluene was the best solvent choice. Lipase Novozyme $435^{\circledR}$ presented esterification capacity against the 2 substrates, and no selectivity for the two diterpenes was demonstrated. Experimental design was an effective strategy to increase the esterification conversion of C\&K with palmitic acid, and a robust GC method for quantification and preparative HPLC for isolating the reaction products was described.

The present results represent a significant improvement in the isolation, esterification and analyses of C\&K and their esters, resulting in faster, high yield and robust methods. This facilitates the recovery of larger quantities of C\&K and their esters in order to further investigate their pharmacology.

Table 3

Conversion for Novoyme $435^{\circledR}$ lipase-catalysed esterification of fatty acids and C\&K.

\begin{tabular}{|c|c|c|c|c|c|c|c|}
\hline Diterpene & \multicolumn{7}{|c|}{ Fatty Acid Conversion (\%) } \\
\hline Kahweol & $85.8 \pm 0.2$ & $86.6 \pm 0.2$ & $87.7 \pm 0.1$ & $87.7 \pm 0.1$ & $87.2 \pm 0.6$ & $86.8 \pm 0.3$ & $88.2 \pm 0.8$ \\
\hline
\end{tabular}

Reaction condition: toluene, $1.5 \mathrm{~mL}$; substrate molar ratio (fatty acid:C\&K), 5:1; lipase content, $110 \mathrm{mg}(7.3 \%, \mathrm{w} / \mathrm{w})$; temperature, $70{ }^{\circ} \mathrm{C}$; stirring, $240 \mathrm{rpm}$; and reaction time, 3 days. All chromatograms and mass spectra available in Supplementary Information (Figs. S9-S14). 


\section{Acknowledgments}

The authors wish to thank FAPERJ, CNPq, Embrapa Café and CAPES for financial support, Dr. Luciana Dalla Vechia Bastos and Dr. Luiz Antônio d'Avila (Laboratório de Combustíveis e Derivados de Petróleo, EQ, UFRJ, RJ, Brazil) for laboratory facilities used to calculate the Hansen Solubility Parameters, and Dr. Bárbara Vasconcellos da Silva and Dr. Raul Rodriguéz (Laboratório de Produtos Naturais, IQ, UFRJ, RJ, Brazil) for supporting in the HPLC preparative analysis.

\section{Conflict of interest}

The authors have declared that there is no conflict of interest.

\section{Appendix A. Supplementary data}

Supplementary data associated with this article can be found, in the online version, at http://dx.doi.org/10.1016/j.foodchem.2018.03.111.

\section{References}

Adachi, S., Nagae, K., \& Matsuno, R. (1999). Lipase-catalyzed condensation of erythritol and medium-chain fatty acids in acetonitrile with low water content. Journal of Molecular Catalysis B: Enzymatic, 6, 21-27.

Aguieiras, E. C. G., Cavalcanti-Oliveira, E. D., \& Freire, D. M. G. (2015). Current status and new developments of biodiesel production using fungal lipases. Fuel, 159, 52-67.

Belandria, V., Oliveira, P. M. A., Chartier, A., Rabi, J. A., Oliveira, A. L., \& Bostyn, S. (2016). Pressurized-fluid extraction of cafestol and kahweol diterpenes from green coffee. Innovative Food Science and Emerging Technologies, 37, 145-152.

Buchmann, S., Küchenmeister, G., Kölling-Speer, I., \& Speer, K. (2010, October). Fast Method for the Quantification of 16-O-Methylcafestol in Roasted Coffee. Conference paper at the 23rd International Conference on Coffee Science, Bali, IDN.

Butt, M. S., \& Sultan, M. T. (2011). Coffee and its consumption: Benefits and risks. Critical Reviews in Food Science and Nutrition, 51, 363-373.

Castro, H. F., \& Anderson, W. A. (1995). Fine Chemicals by biotransformation using lipases. Química Nova, 18, 544-554.

Chartier, A., Beaumesnil, M., Oliveira, A. L., Elfakir, C., \& Bostyn, S. (2013). Optimization of the isolation and quantification of kahweol and cafestol in green coffee oil. Talanta, $117,102-111$.

Dias, R. C. E., Faria, A. F., Mercadante, A. Z., Bragagnolo, N., \& Benassi, M. T. (2013). Comparison of extraction methods for kahweol and cafestol analysis in roasted coffee. Journal of the Brazilian Chemical Society, 24, 492-499.

Duan, Z.-Q., Wei, D., \& Liu, D.-H. (2010). The solvent influence on the positional selectivity of Novozyme 435 during 1,3-diolein synthesis by esterification. Bioresource Technology, 101, 2568-2571.

Erny, G. L., Moeenfard, M., \& Alves, A. (2015). Liquid chromatography with diode array detection combined with spectral deconvolution for the analysis of some diterpene esters in Arabica coffee brew. Journal of Separation Science, 38, 612-620.

Finotello, C., Forzato, C., Gasparini, A., Mammi, S., Navarini, L., \& Schievano, E. (2017). NMR quantification of 16-O-methylcafestol and kahweol in Coffea canephora var. robusta beans from different geographical origins. Food Control, 75, 62-69.

Franssen, M. C. R., Steunenberg, P., Scott, E. L., Zuilhof, H., \& Sanders, J. P. M. (2013). Immobilised enzymes in biorenewables production. Chemical Society Reviews, 42, 6491-6533.

Hansen, C. M. (2007). Hansen solubility parameters: a user's handbook (2nd ed.). Boca Raton: CRC Press, Taylor and Francis Group (Chapter 1).

He, W. S., Jia, C. S., Ma, Y., Yang, Y. B., Zhang, X. M., Feng, B., \& Yue, L. (2010). Lipasecatalysed synthesis of phytostanyl esters in non-aqueous medium. Journal of Molecular Catalysis B: Enzymatic, 67, 60-67.

Higgins, L. G., Cavin, C., Itoh, K., Yamamoto, M., \& Hayes, J. D. (2008). Induction of cancer chemopreventive enzymes by coffee is mediated by transcription factor Nrf2. Evidence that the coffee-specific diterpenes cafestol and kahweol confer protection against acrolein. Toxicology and Applied Pharmacology, 226, 328-337.

Huber, W. W., Teitel, C. H., Coles, B. F., King, R. S., Wiese, F. W., Kaderlik, K. R., Casciano, D. A., Shaddock, J. G., Mulder, G. J., Ilett, K. F., \& Kadlubar, F. F. (2004). Potential chemoprotective effects of the coffee components kahweol and cafestol palmitates via modification of hepatic N-acetyltransferase and glutathione S-transferase activities. Environmental and Molecular Mutagenenesis, 44, 265-276.
Itabaiana Junior, I., Sutili, F. K., Leite, S. G. F., Gonçalves, K. M., Cordeiro, Y., Leal, I. C. R., Miranda, L. S. M., Ojeda, M., Luque, R., \& Souza, R. O. M. A. (2013). Continuous flow valorization of fatty acid waste using silica-immobilized lipases. Green Chemistry, 15, 518-524.

Kaufmann, H. P., \& Hamsagar, R. S. (1962). Zur Kenntnis der Lipoide der Kaffeebohne I: Über Fettsäure-Ester des Cafestols. Fette, Seifen, Anstrichmittel, 64, 206-213.

Kurzrock, T., \& Speer, K. (2001). Diterpenes and diterpene esters in coffee. Food Reviews International, 17, 433-450.

Laane, C., Boeren, S., Vos, K., \& Veeger, C. (2009). Rules for optimization of biocatalysis in organic solvents. Biotechnology and Bioengineering, 102, 1-8.

Lam, L. K. T., Sparnins, V. L., \& Wattenberg, L. W. (1982). Isolation and identification of kahweol palmitate and cafestol palmitate as active constituents of green coffee beans that enhance Glutathione S-Transferase activity in the mouse. Cancer Research, 42, 1193-1198.

Lam, L. K. T., Sparnins, V. L., \& Wattenberg, L. W. (1987). Effects of derivatives of kahweol and cafestol on the activity of glutathione S-transferase in mice. Journal of Medicinal Chemistry, 30, 1399-1403.

Lee, A., Chaibakhsh, N., Rahman, M. B. A., Basri, M., \& Tejoa, B. A. (2010). Optimized enzymatic synthesis of levulinate ester in solvent-free system. Industrial Crops and Products, 32, 246-251.

Lee, K. J., \& Jeong, J. G. (2007). Protective effects of kahweol and cafestol against hydrogen peroxide-induced oxidative stress and DNA damage. Toxicology Letters, 173, 291-297.

Li, C., Sun, J., Li, T., Liu, S.-Q., \& Huang, D. (2014). Chemical and enzymatic synthesis of a library of 2-phenethyl esters and their sensory attributes. Food Chemistry, 154, 205-210.

Liu, Y., Zhang, X., Tan, H., Yan, Y., \& Hammed, B. H. (2010). Effect of pretreatment by different organic solvents on esterification activity and conformation of immobilized Pseudomonas cepacia lipase. Process Biochemistry, 45, 1176-1180.

Majer, B. J., Hofer, E., Cavin, C., Lhoste, E., Uhl, M., Glatt, H. R., Meinl, W., \& Knasmüller, S. (2005). Coffee diterpenes prevent the genotoxic effects of 2-amino-1-methyl-6phenylimidazo[4,5-b]pyridine (PhIP) and N-nitrosodimethylamine in a human derived liver cell line (HepG2). Food and Chemical Toxicology, 43, 433-441.

McMahon, M., Itoh, K., Yamamoto, M., Chanas, S. A., Henderson, C. J., McLellan, L. I., Wolf, C. R., Cavin, C., \& Hayes, J. D. (2001). The cap 'n' collar basic leucine zipper transcription factor Nrf2 (NF-E2 p45-related factor 2) controls both constitutive and inducible expression of intestinal detoxification and glutathione biosynthetic enzymes. Cancer Research, 61, 3299-3307.

Moeenfard, M., Cortez, A., Machado, V., Costa, R., Luís, C., Coelho, P., Soares, R., Alves, A., Borges, N., \& Santos, A. (2016). Anti-angiogenic properties of cafestol and kahweol palmitate diterpene esters. Journal of Cellular Biochemistry, 117, 2748-2756.

Monsalve, L. N., Rosselli, S., Bruno, M., \& Baldessari, A. (2005). Enzyme-catalysed transformations of ent-kaurane diterpenoids. European Journal of Organic Chemistry, 2005, 2106-2115.

Muhammad, I., Takamatsu, S., Mustafa, J., Khan, S. I., Kham, I. A., Samoylenko, V., Mossa, J. S., El-Feraly, F. S., \& Dunbar, D. C. (2008). COX-2 inhibitory activity of cafestol and analogs from coffee beans. Natural Product Communications, 3, 11-16.

Novaes, F. J. M., Oigman, S. S., Souza, R. O. M. A., Rezende, C. M., \& Aquino Neto, F. R. (2015). New approaches on the analyses of thermolabile coffee diterpenes by gas chromatography and its relationship with cup quality. Talanta, 139, 159-166.

Otto, R. T., Scheib, H., Bornscheuer, U. T., Pleiss, J., Syldatk, C., \& Schmid, R. D. (2000). Substrate specificity of lipase B from Candida antarctica in the synthesis of arylaliphatic glycolipids. Journal of Molecular Catalysis B: Enzymatic, 8, 201-211.

Soo, E. L., Salleh, A. B., Basri, M., Rahman, R. N. Z. A., \& Kamaruddin, K. (2004). Response surface methodological study on lipase-catalyzed synthesis of amino acid surfactants. Process Biochemistry, 39, 1511-1518.

Soultani, S., Engasser, J.-M., \& Ghoul, M. (2001). Effect of acyl donor chain length and sugar acyl donor molar ratio on enzymatic synthesis of fatty acid fructose esters. Journal of Molecular Catalysis B: Enzymatic, 11, 725-731.

Speer, K., \& Kölling-Speer, I. (2006). The lipid fraction of the coffee bean. Brazilian Journal of Plant Physiology, 18, 201-216.

Su, F., Li, G.-L., Fan, Y.-L., \& Yan, Y.-J. (2015). Enhancing biodiesel production via a synergic effect between immobilized Rhizopus oryzae lipase and Novozym 435. Fuel Processing Technology, 137, 298-304.

Tsukui, A., Santos Júnior, H. M., Oigman, S. S., Souza, R. O. M. A., \& Rezende, C. M. (2014). Microwave-assisted extraction of green coffee oil and quantification of diterpenes by HPLC. Food Chemistry, 164, 266-271.

Yang, C., Wang, F., Lan, D., Whiteley, C., Yang, B., \& Wang, Y. (2012). Effects of organic solvents on activity and conformation of recombinant Candida antarctica lipase A produced by Pichia pastoris. Process Biochemistry, 47, 533-537.

Zhu, L., Luo, J., \& Hong, R. (2014). Total synthesis of ( \pm )-cafestol: a late-stage construction of the furan ring inspired by a biosynthesis strategy. Organic Letters, 16, 2162-2165. 